THÉMATA. Revista de Filosofía

$\mathrm{N}^{\mathrm{o}} 49$, Enero-junio (2014) pp.: 51-74

ISSN: 0212-8365 e-ISSN: 2253-900X

doi: $10.12795 /$ themata.2014.i49.03

\title{
INVESTIGACIONES ACERCA DE LA ESTRUCTURA CONFLICTIVA DEL EREIGNIS EN BEITRÄGE ZUR PHILOSOPHIE DE MARTIN HEIDEGGER
}

\author{
RESEARCH ON THE CONFLICTING STRUCTURE OF EREIGNIS IN \\ MARTIN HEIDEGGER'S BEITRÄGE ZUR PHILOSOPHIE
}

\author{
Leticia Basso Monteverde ${ }^{1}$ \\ UNMdP/AAdIE-CONICET ${ }^{2}$ (Argentina)
}

Recibido: 05-08-2013

Aceptado: 30-12-2013

\begin{abstract}
Resumen: En este artículo nos introducimos en la obra de Martin Heidegger Beiträge zur Philosophie para interpretar el concepto de Ereignis. Pues bien, consideramos que la constitución de dicho concepto presenta las bases para pensar el problema de la diferencia. Por medio de esta vía hermenéutica, presentada a través de la idea de la estructura conflictiva del Ereignis, exponemos nuestra comprensión del tránsito del Dasein al Ereignis. De este modo, pretendemos aclarar el sentido de la reformulación de la estructura trascendental del Dasein en el tiempo-espacio que la estructura del Ereignis aporta.
\end{abstract}

Palabras-clave: Heidegger, Ereignis, conflicto, estructura, diferencia.

Abstract: In this article we introduce on Martin Heidegger's work Beiträge
zur Philosophie to interpret the concept of Ereignis. Well, we consider that
the constitution of this concept lays the groundwork for think the problem

[1] (leticiabassomonteverde@gmail.com) Doctora en Filosofía por la Universidad de Buenos Aires y becaria Post-doctoral del CONICET. Ha realizado estancias de investigación en la Universidad Complutense de Madrid. Sus áreas de trabajo son la fenomenología y la hermenéutica. Su investigación se centra en la idea de una continuidad en la obra de Heidegger a partir de una comparación del las estructuras del Dasein y el Ereignis. Es miembro de la Asociación Argentina de Investigaciones Éticas (AAdIE) y de la Sociedad Iberoamericana de Estudios Heideggerianos (SIEH). Es investigadora en la Universidad Nacional de Mar del Plata y co-editora de los libros: Texto, significado y mundo. Aproximaciones hermenéuticas y fenomenológicas, Mar del Plata, UNMdP, 2012; Acontecimiento y tradición. Fundamentos de la cultura, Mar del Plata, UNMdP, 2014. Ha publicado diversos artículos acerca de su investigación en revistas nacionales e internacionales.

[2] Universidad Nacional de Mar del Plata/Asociación Argentina de Investigaciones Éticas-Consejo Nacional de Investigaciones Científicas y Técnicas. 
of the difference. By this hermeneutics way, presented here across the idea of the conflicting structure of Ereignis, we expose our understanding of the transit through Dasein to Ereignis. In this way, we aim to clarify the sense of the reformulation of the transcendental structure of Dasein in the timespace structure that provides the Ereignis.

Key-words: Heidegger, Ereignis, conflict, structure, difference.

\section{Introducción a los Beiträge zur Philosophie}

Con Beiträge zur Philosophie. (Vom Ereignis) (1936-38) Heidegger emprende un nuevo modo de pensar plasmado en un discurso aforístico y poético. Tal discurso no se caracteriza por una argumentación proposicional, sino por una escritura fragmentaria de estilo críptico. Los pensamientos del autor fluyen a medida que la interrogación sigue un curso de libre exploración. De esta manera, se aleja del uso forzado que implica una explicación deductiva. $\mathrm{El}$ autor intenta desarrollar un tipo de ejercicio meditativo que no delimite lo que aborda. No obstante, recae en un lenguaje hermético que dificulta su seguimiento. Aunque, vale la pena introducirse en este camino alternativo porque allí se descubren matices que hacen un aporte considerable a la comprensión de aquello que llama "lo impensado o por pensar".

Por otro lado, el tratado no se realiza con una intención didáctica pues, más bien, ensaya un recorrido personal. Aún así, logra por medio de cierta insistencia y algunas indicaciones clarificar su sentido y propósito. Del hecho de que carezca de una lógica, analítica u organización tradicional, no se sigue que prescinda de otro tipo de orden y rigurosidad. Franco Volpi comenta en su escrito póstumo, Martin Heidegger. Aportes a la filosofía: "Éste representa el intento sistemático más orgánico y coherente -tras la Kehre, o precisamente después de la interrupción del proyecto de Sein und Zeit y tras el intermedio político del Rectorado de los años 1933/34- de retomar la problemática que debería haber sido tratada en la parte del opus magnum que había quedado inédita."3 Con todo, sea por el influjo de la Kehre como por algunos cambios metodológicos y estructurales de los Beiträge, Heidegger vuelve a estas cuestiones de otra manera.

Debido a las críticas que en su momento sufrió Sein und Zeit en el ámbito académico y a los comentarios desalentadores de Jaspers acerca del esbozo de la tercera parte de la obra, el filósofo decide resguardar sus investigaciones del ámbito público. La escritura de los Beiträge surge en su refugio de Todtnauberg y se caracteriza por el silencio, la privacidad y el aura por poco clandestina en la cual se desarrolla. Dicho manuscrito sólo fue conocido, entonces, por unos pocos a los cuales Heidegger confía su secreto. De este modo, a la par de su labor docente en la Universidad de Friburgo -en donde experimenta

[3] Volpi, Franco. Martin Heidegger. Aportes a la filosofía, Madrid, Maia Ediciones, 2010, p. 19.

THÉMATA. Revista de Filosofía, Nº49 enero-junio (2014) pp.: 51-74 doi: 10.12795/themata.2014.i49.03 
con cautela las reacciones del auditorio ante su nuevo camino- el filósofo se dedica a la escritura y la revisión de este texto. Pese a su explosión enérgica y creativa éste se gesta en un período de crisis del filósofo y recién se publica, por mandato del autor, luego de su muerte en 1989 -a cien años de su nacimiento. Heidegger así lo decide pues no cree que sea apreciado en su tiempo. Además considera necesario que previamente se publiquen una serie de trabajos para comprenderlo. El carácter preparatorio y, quizás, provisional que tiene este escrito le impide tener en cuenta la posibilidad de revelar tal investigación. A esto se suman las críticas de algunos de sus viejos discípulos, quienes desestiman la jerga y la necesidad de la llamada Kehre.

A Beiträge zur Philosophie le siguen una serie de trabajos que continúan con los temas aquí presentados: Besinnung (1938/39), Geschichte des Seyns (1938/40), Über den Anfang (1941), Das Ereignis (1941/42) y Die Stege des Anfangs (1944). Estos trabajos -recientemente publicados o en vías de publicación, en el último caso- amplían simplemente la descripción de algunos aspectos del proyecto elaborado. Algunos pensadores consideran que estos tratados no aportan nada nuevo respecto de lo que en el anterior se inaugura. Incluso, Franco Volpi indica que obscurecen y terminan por hacer naufragar el otro pensar. Lo cierto es que más allá de su recepción tardía -sea por la incomprensión y desinterés de muchos estudiosos del primer período como por el seguimiento y estudio minucioso reflejado en las últimas obras colectivas que otros le dedican en la actualidad- el filósofo decide develar décadas después de su concepción sólo algunos vestigios de esa parte de su obra.

Todo esto acrecienta las expectativas de los estudiosos y adeptos al segundo período, que antes de su publicación ya consideran a los Beiträge zur Philosophie la segunda gran obra del filósofo y, posiblemente, la continuación de la primera. Indubitablemente en este escrito se encuentra la clave para comprender toda la obra del filósofo; el concepto que explicita de forma originaria el problema del ser. Sin embargo, todavía no se ha elaborado el entramado argumentativo preciso que dé cuenta de la unidad del pensar heideggeriano. Sabemos que esta tarea puede considerarse demasiado pretensiosa, pero al dejarla de lado tal vez se pierda de vista algún componente que eche luces a la cuestión. Bajo estas condiciones sigue en pie la propuesta diseñada en seis ensambles (Fügungen) o fugas (Fugen) a través de los cuales Heidegger sostiene que se alcanzarán el tránsito al "otro comienzo del pensar" y el acceso al ser en su esenciarse. La arquitectura de esta grandilocuente obra invita a presenciar a través de 281 parágrafos los encubrimientos de la metafísica para superar por medio de una transformación interna el viejo pensar.

Ahora bien, más allá de estos aspectos que completan el panorama que Heidegger quiere trazar a nosotros nos interesa, particularmente, reconstruir y problematizar el fenómeno que allí se configura y que entre los pasajes poéticos 
tiene lugar: el Ereignis. ${ }^{4}$ A nuestro juicio, la constitución estructural de dicho fenómeno presenta las bases para pensar de forma adecuada la cuestión de la diferencia. Esto quiere decir, que Heidegger logra articular con el análisis del fenómeno del Ereignis el proceso mismo de la manifestación del ser desde su determinación en el ente. Ser y ente se exponen en la encrucijada del Ereignis a partir de la dinámica propia de la donación. Pues bien, con la descripción fenomenológica del cruce de las dimensiones del Ereignis encontramos una forma de dar cuenta de la donación (Gegebenheit) y la sustracción (Entzug) implícita en la diferencia.

Por medio de esta vía interpretativa, que aquí presentaremos a través de la idea de la estructura conflictiva del Ereignis, intentaremos exponer en detalle nuestra comprensión del tránsito del Dasein al Ereignis -o sea la unidad de la obra de Heidegger. Tal vez, por medio de esta lectura logremos aportar algo nuevo al debate acerca de la continuidad de la obra del filósofo o, en su defecto, por lo menos aclarar un poco el sentido de la reformulación de la estructura trascendental del Dasein en el tiempo-espacio que la estructura del Ereignis aporta.

\section{Caracterización del Ereignis}

\subsection{Etimología y derivas semánticas del concepto de Ereignis}

En el discurso heideggeriano el término "Ereignis" porta una carga significativa realmente compleja que excede el sentido y la referencia de la palabra en su contexto habitual. Heidegger indica que dicho término adquiere un significado en su pensar que lo hace prácticamente intraducible. Como es común en el discurso del filósofo, el término es desmantelado y ensamblado con el fin de resignificar sus partes, acercándolas a su sentido original. De este modo, Heidegger encuentra una forma más atinada de presentar el contenido semántico pretendido.

El concepto de "Ereignis" se viene gestando desde comienzos de su labor filosófica y sufre múltiples obstáculos, progresos y retrocesos del pensar, que lo llevan -incluso- a resurgir de las cenizas gracias a la Kehre. Es importante destacar que con el término Heidegger intenta describir un fenómeno, algo que acontece en la experiencia y que sólo puede describirse genuinamente por medio de la fenomenología. "Ereignis" no indica una noción que trascienda lo

\footnotetext{
[4] El concepto de Ereignis -tal como lo comprende en su reelaboración de los años 30-aparece públicamente con el peso que la noción tiene recién a finales de la década del '50 - comienzos del '60. Específicamente en la conferencia de Friburgo del 31 de enero de 1962 Zeit und Sein y en el seminario que se dictó continuando la conferencia en septiembre del mismo año en Todtnauberg publicados en Zur Sache des Denkens. En aquel tiempo, tal como señala Richard Capobianco, “... su discurso sobre el Ereignis es más calmo, maduro; ya no tiene una retórica extravagante y un tono cuasi apocalíptico." (Cfr. Capobianco, Richard. Engaging Heidegger, Toronto, University of Toronto Press, 2010, p. 44.) Sin embargo, pierde la sistematicidad, la profundidad y el interés en el proyecto que en 1936 Heidegger emprende.
}

THÉMATA. Revista de Filosofía, N 49 enero-junio (2014) pp.: 51-74

doi: 10.12795/themata.2014.i49.03 
fáctico y se corresponda con consideraciones de orden teórico. "Ereignis" no representa un proceso abstracto y meramente formal que pueda resumirse o transcribirse en una serie de categorías. Con el término no se hace otra cosa más que abordar un fenómeno que emerge y se configura a partir de la relación entre ser y pensar, es decir, como acontecer del ser en lo acontecido y lo aconteciente del y para el Dasein. De hecho, la dificultad yace en la idea de expresar un suceso singular que caracteriza la relación más esencial e íntima entre el Dasein y el Seyn.

Heidegger juega con la profundidad del "Ereignis" y los diversos niveles de sentido que el término tiene en un diálogo continuo con los matices que su origen etimológico nos brinda. En efecto, a través de un análisis filológico Heidegger descompone el vocablo alemán en la forma "Er-eignis" y observa que el prefijo " $E r$ " indica un matiz intensivo bajo la idea "hacer algo", "hacer surgir algo", "producir algo" y la parte "eignis" deriva de "eigen" y "eignen" que en alemán significa "propio". Este motivo le permite a Heidegger desviar el sentido ordinario del término "acontecimiento", "acaecimiento", "evento" hacia el influjo semántico de la apropiación. Asimismo, la procedencia etimológica de Ereignis de eräugen -que significa captar con la mirada, pero también poner a la vista y, por lo tanto, mostrar y mostrarse, acontecer- relaciona lo propio con la idea de lo propicio. Esto se debe a que “...eräugen expresa lo que acontece en el instante (Augen-blick) de hallar con la mirada lo que se a-delanta a ser mirado: el propiciarse de la visión." 5 De este modo, pensadores como Félix Duque traducen Ereignis por "acaecimiento propicio"6 y destacan que "...lo propicio propicia y lo así propiciado es lo propio y apropiado del ser-ahí [Dasein]." Con esto se recalca cómo el Ereignis busca ser él mismo Ereignis.

A propósito Heidegger dice en un pasaje de Zeit und Sein: "Lo nombrado con el nombre alemán "das Ereignis” no podemos representárnoslo ya tomando como hilo conductor el significado usual de la palabra; pues éste la entiende en el sentido de evento (Geschehnis) y suceso (Vorkommnis) no desde el apropiarse como esclarecedor y salvaguardante extender y destinar." $\mathrm{Al}$ respecto Roberto Walton dice en un artículo en la compilación Heidegger hoy: "el Dasein avista (er-blickt) el ser, o alcanza el ser con la mirada, y a la vez el ser

[5] Véase la introducción de Borges Duarte en Herrmann, Friedrich Wilhelm von. La segunda mitad de Ser y Tiempo. Sobre los problemas fundamentales de la Fenomenología de Heidegger, Madrid, Trotta, 1997, p. 20.

[6] Otras de las traducciones españolas de Ereignis son: advenimiento apropiador, acaecimiento apropiador, acontecimiento apropiante y evento apropiador, entre otras. En ese trabajo preferimos mantener el término en alemán para no reducir su complejidad semántica.

[7] Idem. (Cita $\left.\mathrm{N}^{\circ} 4\right)$

[8] Heidegger, Martin. Zur Sache des Denkens, Frankfurt am Main, Vittorio Klostermann, GA 14, 2007, pp. 25-26.

THÉMATA. Revista de Filosofía, Nº 49 enero-junio (2014) pp.: 51-74

doi: 10.12795/themata.2014.i49.03 
nos avista de modo que hay un recíproco avistarse." ${ }^{9}$ De esta manera y como ya vimos, la procedencia etimológica le permite a Heidegger rescatar que avistar no significa simplemente ver algo (Etwas sehen), sino que el verbo reposa en mirar hacia lo que, desde lo visto, nos dirige la mirada propiamente.

\subsection{Comprensión inicial del fenómeno y sus partes}

Una aproximación a los Beiträge zur Philosophie nos permitirá rescatar, en toda su complejidad, la correlación que entre Seyn y Dasein acontece. Por consiguiente, si nos introducimos en la obra y logramos reconocer las tensiones que en cada ensamble se presentan, será posible reconstruir la estructura del fenómeno en el ámbito preciso en el cual se gesta. Sin duda alguna, por medio del problema de la donación del ser (de la oscilación entre un mostrarse y ocultarse) se percibe tanto el origen como la constitución del Ereignis. Investigar el problema de la donación facilita estudiar las dos partes de la correlación de acuerdo a su acción y reacción en la dinámica que se activa con la diferencia propia del despliegue del ser (Entfaltung des Seyns).

Con el fenómeno del Ereignis se abre el campo ontológico a la dimensión del Seyn. Este ámbito de sentido le otorga a Heidegger la posibilidad de redefinir el comportamiento del Dasein para aclaran algunas cuestiones oscuras de la elaboración de Sein und Zeit; entre estas, las de la trascendencia y el horizonte de sentido en el que se emplaza la diferencia. Así pues, a lo largo de cada ensamble se van descubriendo determinados aspectos programáticos que hacen a la conformación del fenómeno y que posicionan al Dasein de otra manera a través de ciertas disposiciones conocidas; ahora modificadas o redireccionadas. Por lo tanto, por medio de lo que con cada ensamble se gana en el proceso de acceso al "otro comienzo del pensar", se descubre -a medida que se realiza- la constitución integral de dicho fenómeno. Cada uno de los ensambles aporta, de forma complementaria y sin seguir un lineamiento cronológico, un paso esencial en función al fenómeno que estamos abordando, y eso incluye al papel del Dasein en él.

Ahora bien, una forma de entender la oscilación que va del Dasein al Seyn y del Seyn al Dasein reside en la unidad y el equilibrio de esta relación que el filósofo indica a través de un punto medio (Mitte). Como dice Heidegger en Die Sprache: "El medio de ambos es la intimidad. Lo medio entre dos, nuestro idioma alemán lo llama Zwischen." "Vale la pena destacar que este tipo de intimidad se caracteriza por su distinción. Heidegger aprovecha la idea de la diferencia para subrayar que la relación no permite una fusión de las partes

[9] Cfr. Walton, Roberto. El camino hacia lo inaparente. En Alfredo Rocha de la Torre (ed.) Heidegger hoy. Estudios y perspectivas, Buenos Aires, Grama, 2011, p. 190.

[10] Heidegger, Martin. Unterwegs zur Sprache, Frankfurt am Main, Vittorio Klostermann, GA 12,1985, p. 22.

THÉMATA. Revista de Filosofía, No 49 enero-junio (2014) pp.: 51-74 doi: 10.12795/themata.2014.i49.03 
pero tampoco su total independencia. En el medio de la diferencia las partes se traspasan y dan lugar al cruce desde donde lo distinto se hace uno sin perder su esencia, como el acontecer de un doble y recíproco apropiarse -sich (an) eignen. Tanto el Dasein como el Seyn son en la relación, pues ninguno de ellos pre-existe a la instancia del Ereignis.

De este modo, el filósofo describe que la escucha (Hören) del Dasein para la pertenencia al Seyn procede de la interpelación (Anspruch) de este último en el llamado. El Dasein requiere ser despertado por el llamado del Seyn para ser en lo propio y apropiar lo que es siendo. Heidegger señala que un golpe (Stoss) lo repone en la donación esclarecedora-ocultante. Por otro lado, el Seyn precisa del Dasein porque sólo se expresa a través de él, ya que el Dasein lo transporta a lo abierto y lo retira de su ocultación para mantenerlo en lo propio de sí por la custodia (Verwahrung) de su verdad.

En Der Satz der Identität ${ }^{11}$ el filósofo dice que la "mutua pertenencia" (Zusammengehören) debe acentuar el segundo término, la "pertenencia", porque lo mutuo es ahora determinado a partir de ella. Seguido, plantea que “... se debe experimentar lo mutuo a partir de la pertenencia"12 porque en ella se funda la dimensión de lo simple en la relación Dasein-Seyn. Heidegger entiende que la mutua pertenencia del Dasein y el Seyn muestra una forma de ser en propiedad; de darse al otro sin perder lo propio. Es más, siendo propio a partir del otro. Esta es una expropiación-apropiación que se transpropia.

Es muy importante comprender este tipo de relación porque representa un factor fundamental en la conformación del Ereignis. La relación genera las condiciones particulares de la dimensión en la que se emplaza el fenómeno, y la modalidad y el contenido a través de los cuales éste se realiza. Ciertamente allí, surge la provocación alternante (wechselseitige Herausforderung) que por causa de la apropiación (Er-eignung) y expropiación (Ent-eignung) compone y descompone a la diferencia. Con el Ereignis Heidegger aporta la idea más sofisticada de una transpropiación (Über-eignung) del Dasein y el Seyn en la co-pertenencia (Zusammengehören). En este cruce se experimenta la donación en su envío y sustracción, debido a que el Ereignis se emplaza en el espacio de juego donde tiempo y ser convergen.

Por ejemplo, en la conferencia Zeit und Sein Heidegger dice: “...en el destinar [Schicken] del destino del ser, en el ofrecer o extender [Reichen] del tiempo se muestra un apropiarse, un transpropiarse, que lo es del ser como presencia y del tiempo como ámbito de lo abierto en lo que uno y otro tienen de propio [...] en su recíproca copertenencia."13 Este fenómeno comprende la

[11] Heidegger, Martin. Identidad y Diferencia- Identität und Differenz, edición bilingüe, trad. H. Cortés y A. Leyte, España, Anthropos, 1990, p. 73.

[12] Idem.

[13] Heidegger, Martin. Zur Sache des Denkens, op. cit., p. 24.

THÉMATA. Revista de Filosofía, Nº49 enero-junio (2014) pp.: 51-74 doi: 10.12795/themata.2014.i49.03 
versión renovada de la trascendencia y contiene a la verdad del ser en un horizonte originario de continua oscilación. De hecho, en Vom Wesen des Grundes Heidegger presenta a la trascendencia como el proyectarse hacia lo proyectado que nos determina. Incluso, especifica que el proceso se completará cuando comprendamos efectivamente a la trascendencia. ${ }^{14}$

Esta alusión a una compresión originaria de la trascendencia se concreta en los Beiträge..$^{15}$ El filósofo plantea una excedencia que en el fenómeno de la trascendencia indica la previa pertenencia del Dasein al Seyn. Tal excedencia permite, en principio, el traspasamiento del ente. De hecho, para acceder a la comprensión del ser del ente, debemos primero estar insertos en el ámbito del ser. Ya veremos luego en el apartado (3.1.) que para concretar la proyección (Entwurf), el Dasein requiere de la yección (Zuwurf) del Seyn. La trascendencia se refleja en el lanzarse y el sustraerse que desde el Seyn determinan al $D a$ sein. Por ende, la trascendencia que se anuncia en el tratado de 1929 no hace más que adelantar el sentido de la doble trascendencia que se da en el Ereignis entre el Dasein y el Seyn.

Afortunadamente la trascendencia se da en el horizonte de sentido apropiado para captar la diferencia. Pues bien, cuando Heidegger se refiere al ámbito originario (ursprünglicher Gegend) del que proceden y en el cual se fundan las cosas, no hace más que reconfigurar la noción de horizonte-exstático y trascendental en el plano fundante de la donación. De este modo, sostenemos -tal como lo hace Roberto Walton ${ }^{16}$ que en el contexto del "otro pensar" lo abierto presenta otra forma de articular las relaciones significativas a concretarse en el mundo. Tal forma de articular aparece previamente como un ensamblar indeterminado del entramado inaparente del cual surgen las cosas.

Por lo tanto, consideramos que el ámbito originario es también horizontal en el sentido de que estructura y delimita la dimensión en cuestión. Este tipo de delimitación (un poner límites que tiene que ver con un destrabar) se relaciona con lo esencial y lo inesencial, la verdad y la no-verdad. No obstante, cuando Heidegger se refiere a esta doble dimensión, la esencial y la inesencial, evita el sentido ordinario de "lo dual" porque no hace más que realzar la escisión en el fenómeno originario. De hecho, sólo podemos hablar de una distinción como efecto de la unidad de la diferencia. Aunque, como bien sabemos, tal distinción no es otra cosa que el desdoblamiento de ente y ser en la intimidad de la diferencia. En Der Satz der Identität $t^{17}$ Heidegger insiste en que la mutua pertenencia de $D a$ sein y Seyn debe comprenderse en una dimensión para no ejercer la violencia de

[14] Heidegger, Martin. Wegmarken, Frankfurt am Main, Vittorio Klostermann, GA 9, 1976, p. 166.

[15] Heidegger, Martin. Beiträge zur Philosophie (Vom Ereignis), Frankfurt am Main, Vittorio Klostermann, GA 65, 1994, p. 217.

[16] Walton, Roberto. El camino hacia lo inaparente, op. cit., p. 201-205.

[17] Heidegger, Martin. Identidad y Diferencia- Identität und Differenz, op. cit., p. 75.

THÉMATA. Revista de Filosofía, Nº49 enero-junio (2014) pp.: 51-74

doi: 10.12795/themata.2014.i49.03 
la división de un orden conjunto por la integración de las partes. Seyn y Dasein son uno, es decir, tienen sentido en el acaecer conjunto que se retroalimenta y no en una fusión derivada. Por consiguiente, en este nivel de la donación se transgrede toda concepción de entidad aislada para ir más allá de la disociación. De allí se sigue, el sentido de la trascendencia como apropiación o expropiación que por la transpropiación logra mantener la integridad del fenómeno.

Una vez establecida la idea de que la estructura del Ereignis se define por la intimidad de sus partes, en este escrito proponemos un análisis de la constitución del fenómeno a partir de sus dimensiones. Esto se debe a que consideramos que la mejor forma de mostrar la dinámica del Eregnis resulta de la descripción de la función de sus partes en la co-pertenencia. De este modo, el Ereignis se caracteriza por la contra-tensión de sus partes que en su punto medio (Mitte) transitan, por la expropiación de sí, a la apropiación de su esencia. Esto se debe a que sólo en el entre (Zwischen) ocurre la puesta en obra de la verdad. Ya vimos, que en la conferencia Die Sprache Heidegger explica que las partes se atraviesan y forman un medio en el que concuerdan y son íntimas. Así, por la intimidad, las partes se distinguen porque en "el entre" reside la diferencia, el inter-medio (Unter-Schied)." 18 La diferencia es una y unitiva, y por ella se concreta toda obra. Heidegger, además, dice que la diferencia es la dimensión donde adviene el Ereignis.

\section{Interpretación de la estructura conflictiva del Ereignis}

\subsection{Constitución y función de las dimensiones del fenómeno}

Para elaborar una descripción sistemática de la estructura del Ereignis se requiere contextualizarlo en la instancia originaria de la donación. Por este motivo, debe comprenderse -según nuestro criterio- la cuestión del desdoblamiento del donar y lo donado, que apunta a la relación sintética entre el ser y el ente. Sólo gracias a la revisión del vacilante esenciarse del ser y de su fundamento abismal se obtiene una clave interpretativa coherente respecto del problema de la diferencia en el marco del Seyndenken. Dicha clave le permite al filósofo configurar el fenómeno sin omitir ningún aspecto del asunto en cuestión. Asimismo, la oscilación (Schwingung) del Ereignis y el tipo de ensamblaje (Fuge) de sus dimensiones están determinados por la paradoja inherente al despliegue del ser, que oculta y desoculta su sentido. De aquí se sigue, el origen conflictivo del fenómeno que determina la estructura que a continuación explicaremos.

La idea de un conflicto (Streit) en el fenómeno indica el traspasamiento (Übersteigung) de los opuestos en la relación entre el Seyn y el Dasein. Esto

[18] Heidegger, Martin. Unterwegs zur Sprache, op. cit., p. 22.

THÉMATA. Revista de Filosofía, Nº49 enero-junio (2014) pp.: 51-74 doi: 10.12795/themata.2014.i49.03 
significa que el Ereignis tiene una estructura conflictiva por causa de la relación entre dimensiones que retraen o prolongan, en el sentido de ocultan o desocultan, la donación. La estructura conflictiva procede de la contratendencia (Gegenstrebige) en donde los opuestos no se excluyen sino que se complementan (reúnen) en la contraposición (Auseinandersetzung) armónica de los contrarios. ${ }^{19} \mathrm{El}$ conflicto, a diferencia de la idea de un dilema, descubre que el fenómeno se realiza en el balanceo (Schwung) constante de las dimensiones y no en la selección de una de éstas. Sin duda alguna, Heidegger plantea esta dinámica contra-tensiva con el fin de abrir la estructura al problema de la diferencia, ya que la perspectiva de la oscilación posibilita una comprensión que necesariamente no supera sino que acoge a la misma. En otras palabras, la presencia de la oscilación se adhiere al objetivo de abarcar al Ereignis en sus dimensiones sin socavar el camino a ningún ámbito porque la donación despliega las posibilidades de encontrarse en la verdad y en la no-verdad. De allí en más, basta con experimentar el quiebre para despertar y permanecer en "el entre" del Ereignis. En efecto, recién con el balanceo que enlaza lo abismal podrá el Dasein meditar acerca del vacilante transcurso de la donación.

Ahora bien, siguiendo los lineamientos previamente pautados, podemos establecer que la estructura general del Ereignis se compone de dos dimensiones que expresan el envío y la sustracción de la donación. A continuación esbozaremos las dimensiones que conforman el fenómeno y el detalle de la dinámica que constituye al Ereignis.

Con las formas de la yección-a (Zuwurf) del Seyn y la proyección (Entwurf) del Dasein, ${ }^{20}$ el Ereignis despliega la verdad en la dimensión desocultante de la apropiación. "Puesto a que el ser necesita del hombre para esenciarse y el hombre pertenece al ser [gehört dem Seyn] para realizar su extrema determinación [äußerste Bestimmung] como Da-sein." ${ }^{11}$ En este caso, la yección apropiante ${ }^{22}$ del Seyn, en un lanzamiento (Wurf) de carácter

[19] Para comprender el sentido conflictivo del Ereginis, véanse los análisis de Heidegger del pólemos heraclíteo en: Einführung in die Metaphysik, Frankfurt am Main, Vittorio Klostermann, GA 40, 1983, p. 66. Hölderlins Hymnen. „Germanien” und der „Rhein”, Frankfurt am Main, Vittorio Klostermann, GA 39, 1999, p. 124 ss. y Heraklit. Der Anfang des abendländischen Denkens, Frankfurt am Main, Vittorio Klostermann, GA 55, 1994, p. 141 ss.

[20] Para analizar la estructura del Ereignis en las formas Zuwurf-Entwurf y Kehre-Widerkehre que aparecen en los Beiträge, tuvimos en cuenta las interpretaciones de F-W von Herrmann en: Wege ins Ereignis. Zu Heideggers "Beiträgen zur Philosophie”, Frankfurt am Main, Vittorio Klostermann, 1994, p. 62-63 y Heideggers "Grundprobleme der Phänomenologie". Zur "Zweiten Hälfte" von "Sein und Zeit", Frankfurt am Main, Vittorio Klostermann, 1991, p. 70-71. Y de Roberto Walton en El camino hacia lo inaparente, op. cit., p. 191.

[21] Heidegger, Martin. Beiträge zur Philosophie (Vom Ereignis), op. cit., p. 251.

[22] Hay diversas formas de traducir los movimientos de yección y proyección. Aquí empleamos la versión apropiante-apropiada para la dimensión desocultante y desapropiante-desapropiada para la dimensión ocultante del Ereignis. Otras versiones pueden ser aconteciente-acontecida,

THÉMATA. Revista de Filosofía, Nº 49 enero-junio (2014) pp.: 51-74

doi: 10.12795/themata.2014.i49.03 
Investigaciones acerca de la estructura conflictiva del Ereignis en Beiträge zur philosophie de Martin Heidegger

indeterminado, impela al Dasein a captarlo. El Dasein patentiza el imperar de la yección del Seyn por medio de un temple que lo emplaza bajo cierto encantamiento (Berückung). Entonces, gracias a que el Dasein es arrojado (geworfen) por el ser -desplazado al éxtasis (Entrückung) de apertura al llamado- ${ }^{23}$ logra mantenerse en este ámbito. De esta manera, delimita lo yectado pues instituye el proyecto en un alzado, es decir, ordena lo dado en una forma que se instala.

Heidegger dice en el $§ 122$ de los Beiträge que: "La inauguración a través del proyecto [die Eröffnung duch den Entwurf] es sólo tal cuando sucede como experiencia de la condición de arrojado [Geworfenheit] y con ello de la pertenencia (Zugehörigkeit) al Seyn [...] cuanto más proyectante se hace [je entwerfender er wird], tanto más arrojado [geworfener] es ya el arrojo." ${ }^{44} \mathrm{De}$ este modo, el Dasein efectúa la apropiación (Er-eignung) de la yección, que también es una apropiación de sí en el Ereignis, para transformarse en el custodio de la yección y el fundador del proyecto. Por lo tanto, reunidos en la distensión contratendiente los extremos de la donación, Seyn y Dasein, fundan una versión apropiada del Ereignis.

Por otro lado, por motivo del rehúso (Verweigerung) de lo que debe ofrecerse, la yección se sustrae como yección desapropiante y la proyección deviene en caída como proyección desapropiada. Aquí la verdad se oculta en los ropajes del ente y el Dasein permanece en el extravío (Verlorenheit) que lo mantiene como ser-ausente (Weg-sein). Ser ausente del $D a$, el instante en donde se funda la verdad, significa encontrarse en la inautenticidad del ahí. En este ámbito no se efectúa ni la Kehre en el Dasein ni la Widerkehre en el Seyn. Esto significa que ni el Seyn emerge de lo oculto para emplazarse en el Da-sein ni el Dasein efectúa la inversión necesaria para poner en acto la kerhiger Bezug des Seyns (la relación virante con el ser). Entonces, las partes que componen esta dimensión permanecen ocultas, evitando la comparecencia de la donación y generando el abandono del ser y su, consecuente, encubrimiento en el ente. En este caso, el lanzamiento se retiene y la proyección del Dasein deviene en caída. ${ }^{25}$

propiciador-propiciado, apropiador-apropiado, etc.

[23] En varios pasajes de los Beiträge Heidegger presenta juntos los temples de éxtasis (Entrückung) y encantamiento (Berückung) pues el tiempo-espacio propicio para la fundación de la verdad del ser depende del horizonte abierto entre la proyección exstática del Dasein y la yección encantadora del Seyn. Entrückung y Berückung también pueden traducirse como "desplazamiento" y "emplazamiento", dado a que el desplazamiento alude a la condición de estar fuera, remitirse-a, del éxtasis y el emplazamiento tiene que ver con ese lugar en donde el Dasein encuentra su puesto para la recepción de la donación, en el $D a$. Analizaremos estos temples que caracterizan la dimensión apropiadora del Ereignis en el próximo apartado.

[24] Ibidem, p. 239. (Cita $\mathrm{N}^{\circ} 21$ )

[25] En esta segunda instancia se plasma la sustracción del lanzamiento por la tensión que retiene y la suspensión del proyecto que deviene en encubrimiento.

THÉMATA. Revista de Filosofía, Nº49 enero-junio (2014) pp.: 51-74 doi: 10.12795/themata.2014.i49.03 
Fuera de toda disposición emplazadora de sentido y lejos del contraimpulso o contrabalanceo (Gegenschwung) ${ }^{26}$ que abre al Dasein a la captación, la donación yace encubierta en el Enteignis: la dimensión ocultante de la expropiación (Ent-einung). De este modo y por la tensión contratendiente, los extremos expropiados se separan impidiendo el traspasamiento (Übersteigung) apropiador que como transpropiación (Übereignung) los reúne. No obstante, Heidegger dice que: "El rehúso es la más íntima coacción de la indigencia más originaria, de nuevo inicial, hacia la necesidad de una legítima-defensa [Not-wehr]." ${ }^{27}$ Esto significa, que el rehúso del ser en su yectar sustraído, en realidad, es la asignación para el claro en el que el Dasein se estremece. El rehúso otorga la posibilidad de experimentar la indigencia que despierte al $D a$ sein del olvido del olvido para enfrentar la decisión de una vuelta al ser desde el reconocimiento de su condición carencial.

A la hora de presentar la estructura general de la donación hay que recordar que el Ereignis se compone de estas dos dimensiones. Por esto, es en la puja contraoscilante (Gegenschwingend) de la yección del Seyn y la proyección del Dasein, y del rehúso (Verweigerung) de la yección y el olvido del ser (Seinsvergessenheit) que surge y se sostiene el Ereignis. "Este contrabalanceo de necesitar y pertenecer constituye al ser como Ereignis y lo primero que pensantemente nos incumbe es elevar a la simplicidad del saber y fundar en su verdad la oscilación de este contrabalanceo [die Schwingung dieses Gegenschwunges]." ${ }^{8}$ Sólo con una visión integral del fenómeno, es decir, atendiendo a las dos partes que dan cuenta de la diferencia, se llega a reconstruir debidamente el asunto originario de la donación.

\subsection{Los temples fundamentales que modulan el Ereignis}

Cuando Heidegger reelabora el problema de la diferencia ontológica en el Seynsdenken introduce una nueva forma de comprender la relación entre el Seyn y el Dasein. De este modo, la exposición del filósofo se inicia con el fenómeno en el cual emerge y se sostiene la diferencia por las dos partes que yacen en intimidad. Pues bien, el tipo de acontecer del ser ya no se analiza simplemente a través del Dasein sino a partir del inter-medio que modula el

[26] Mantenemos dentro del espectro de posibilidades la traducción "contraimpulso" (Gegenschwung) porque aporta, más allá de la contraoscilación o contrabalanceo del Ereignis, la idea renovada de un contramovimiento (Gegenbewegung) del Dasein para la apropiación del Seyn. El contraimpulso refiere en los Beiträge a la transformación del Dasein de animal racional al serahí para una captación adecuada del sentido de la donación. Contraimpulso parece más apropiado para denominar esa retro-inversión del Dasein a lo originario.

[27] Ibidem, p. 240.

[28] Ibidem, p. 251.

THÉMATA. Revista de Filosofía, No 49 enero-junio (2014) pp.: 51-74

doi: 10.12795/themata.2014.i49.03 
entramado de sentido del fenómeno entero. En principio, Heidegger estipula el ámbito (Gegend) en donde se instala esta relación en las formas apropiadas y expropiadas que presentamos; el ámbito inaparente y abismal que constituye al fenómeno del Ereignis. Heidegger identifica a este ámbito que ensambla la estructura aconteciente del fenómeno, justamente, con la diferencia.

Recordemos que la diferencia se realiza a través del acercamiento o el alejamiento de sus partes porque en ella se une y separa lo que es contrapuesto. Por ende, "la diferencia es la dimensión"29 donde las partes contratendientes se traspasan, llevándolas a lo que les es propio. Aquí la dimensión no representa una porción extensa y medible por el cálculo. ${ }^{30}$ La dimensión no es la trayectoria que recorre un móvil en una serie sucesiva de ahoras. Sin embargo, en la dimensión que el ámbito originario limita para descubrir la diferencia, tiempo y espacio se configuran como una totalidad ensamblada (Zeit-Raum-Gefüge) en la que se funda la verdad del ser. Por ende, la dimensión o, mejor dicho, las dos dimensiones que componen la estructura del Ereignis en la tensión y la distensión por medio de los movimientos que analizamos previamente, temporalizan y emplazan la donación. Heidegger dice en Die Sprache que: “...la diferencia es la que mesura [Er-messen] la medida de su esencia [Maß ihres Wesens], la que abre a las partes de par en par." ${ }_{11}$

Con todo, para que la verdad del ser emane de lo oculto en una versión descubierta deben concretarse dos temples fundamentales que plasman en el Ereignis la inter-referencia ${ }^{32}$ (Wechselbezug) o doble Kehre. Dos temples que mencionamos previamente y que son muy importantes en esta perspectiva tempo-espacial del Ereignis: el éxtasis (Entrückung) y el encantamiento (Berückung). ${ }^{33}$ Señalamos que estos temples dan cuenta de la inter-referencia porque, como a simple vista se observa, el primero lo aporta Sein und Zeit y

[29] Heidegger, Martin. Unterwegs zur Sprache, op. cit., p. 23.

[30] Pese a que esta concepción de la dimensión no se rige por las propiedades básicas de la naturaleza, Heidegger habla de una medida, magnitud, cercanía, lejanía de espacio y tiempo, aunque lo hace a su manera.

[31] Idem. (Cita $\left.\mathrm{N}^{\circ} 31\right)$

[32] El término "inter-referencia" indica la correspondencia entre los dos períodos de la obra del filósofo (la analítica existencial y el Seynsdenden) que se cristaliza en el Ereignis y da cuenta de la unidad del pensar heideggeriano. Traducimos Wechselbezug como "inter-referencia" para distinguirla del sentido interno a la concepción de Heidegger de una "relación recíproca" entre, por ejemplo Seyn y Dasein. Cuando traducimos "inter-referencia" queremos plantear, al modo de una lectura meta-discursiva, la conexión de Sein un Zeit con los Beiträge zur Philosophie.

[33] Recordamos que Entrückung apunta directamente a un desplazamiento y Berückung a un emplazamiento. Franco Volpi señala en su análisis crítico de los Beiträge que: "el Zeit-Raum produce Entrückungen y Berückungen, dilataciones y contracciones, alejamientos y acercamientos, 'éxtasis' y 'atracciones', en los que el tiempo (con sus tres éxtasis) y el espacio (con sus dimensiones) se articulan abriendo el 'despejamiento' (Lichtung) en el que el Dasein es acontecido y apropiado por el Ser." (Martin Heidegger. Aportes a la filosofía, op. cit., p. 57)

THÉMATA. Revista de Filosofía, No 49 enero-junio (2014) pp.: 51-74

doi: 10.12795/themata.2014.i49.03 
el segundo proviene de los Beiträge zur Philosophie. Antes de introducirnos en el análisis de estos temples, queremos presentar algunas consideraciones respecto de los conceptos de ámbito, movimiento y dimensión que determinan el comportamiento del Dasein en la relación con el Seyn.

En la tercera conferencia de Das Wesen der Sprache ${ }^{34}$ Heidegger retoma estos conceptos trabajados anteriormente en el curso de $1927,{ }^{35}$ aunque ahora contextualizados en el Seynsdenken. El filósofo entiende la noción de ámbito (Gegend) ${ }^{36}$ en el sentido de lo que viene-en-contra (Gegnende), es decir, lo contrapuesto que libera el claro (Lichtung) de lo oculto para que el Dasein lo custodie desde la puesta-en-camino (Be-wëgung). Heidegger dice que sólo el ámbito originario es condición de posibilidad para todo camino. "Él en-camina (be-wëgt); hace don de camino." 37 En efecto, poner-en-camino (Wëgen y Be-wëgen) profundiza la cercanía al origen y conecta al Dasein con el balanceo inherente al Ereignis, ya que según Heidegger wiegen (mecer), wagen (atreverse) y wogen (ondear) nos remiten a eso. ${ }^{38} \mathrm{El}$ Dasein tiene que encaminarse pero no hacia delante sino hacia donde ya se encuentra situado. En efecto, el camino practica un retroceso al origen a partir del recogimiento sobre lo mismo (das Selbe). Bajo esta óptica, Bewëgung a diferencia Bewegung (concepto tradicional de movimiento en el sentido aristotélico) destaca la idea de un movimiento centrado en el recorrido que se determina por la proximidad o vecindad (Nachbarschaft) al ámbito de donación.

Heidegger plantea un análisis del movimiento entre las partes que se oponen (Gegnen) como un estar uno-frente-a-otro-mutuo (Gegen-einander-über) en el que se disponen la cercanía (Nähe) y la lejanía (Ferne). El filósofo señala en Das Wesen der Sprache: "Cuando se piensa la cercanía, aparece la lejanía. Ambas se hallan en una cierta contraposición como distintas magnitudes de la distancia [Abstande] de los objetos. La medición de la magnitud [Größe] se efectúa cuando medimos trayectos [Strecken] según su longitud. Así, la medición de los trayectos medidos está tomada cada vez de una prolongación (Erstreckung) por el cual y a lo largo del cual se calcula el número de unidades en el trayecto medido." 39

Sin embargo, Heidegger deja en claro que los parámetros clásicos empleados por el pensamiento calculador no son los que dan cuenta del sentido

[34] Publicado en Heidegger, Martin. Unterwegs zur Sprache, op. cit., p. 186.

[35] En el $§ 19$ a. $\beta$ de Die Grundprobleme der Phänomenologie 1927, Frankfurt am Main, Vittorio Klostermann, GA 24, 1989.

[36] El concepto Gegend debe comprenderse como el sitio, el paraje o la comarca en donde las cosas se emplazan como estar-frente las unas a las otras. El concepto heideggeriano está vinculado al sentido del pólemos que bajo la traducción de Auseinandersetzung el filósofo rescata.

[37] Heidegger, Martin. Unterwegs zur Sprache, op. cit., p. 186.

[38] Cfr. Ibidem, p. 187.

[39] Ibidem, p. 197.

THÉMATA. Revista de Filosofía, No 49 enero-junio (2014) pp.: 51-74

doi: 10.12795/themata.2014.i49.03 
originario. Las prolongaciones entre cercanía y lejanía se dan en estructuras de tiempo y espacio de otra naturaleza. Para medir las prolongaciones no se requiere atender a las distancias consumadas en los trayectos sino al en-caminar, es decir, al movimiento de contraposición de uno frente al otro de las partes contratendientes. Esto es lo que constituye la esencia misma de la cercanía (die Nahnis). ${ }^{40}$ Heidegger explica en su curso Heraklit que "...lo recorrido por la medida y por el ser medido es la di-mensión. En tal caso, el sentido fundamental, la esencia de la medida, es la amplitud, lo abierto, el extenderse y ampliarse del claro. [...] Solamente una perspectiva de la mirada humana puede abrirse para entrever la medida, esto es, la 'amplitud de tensión' [Spann-Weite]." ${ }^{41}$ Asimismo, en su escrito Zeit und Sein nos dice que: "Dimensión es aquí pensada no sólo como ámbito de la posible medición, sino como el traspasar de un lado a otro, como el ofrendar esclarecedor [Lichtenden Reichen]. Sólo este permite representar y delimitar un ámbito de medida." ${ }^{42} \mathrm{Y}$ tal ofrenda no es otra que la cuarta dimensión que dona a las otras la posibilidad de ser, y mantiene separados y unidos en la contra-tensión a los opuestos. En suma, para que la cercanía encuentre su expresión en el claro, el tiempo temporaliza (die Zeit zeitigt) y el espacio espacializa (der Raum räumt) dando lugar a las cosas y las relaciones entre estas.

Por otro lado, Heidegger rescata el carácter pasivo de la donación en la disposición receptiva del claro en el Dasein. El concepto de Dasein es reformulado en los Beiträge, Heidegger da cuenta de ello a través de la marca que establece separando el término con un guión Da-sein. Al separarlo acentúa el $D a$ para remarcar su aspecto topológico. Esto significa que ahora el concepto de Dasein no se distingue por el carácter modal que insiste en la actividad de una producción de mundo, de una significación del entorno. Ahora el concepto de Dasein resalta la idea de un "ahí", el lugar en donde se reúnen ser y hombre. De este modo, el filósofo acentúa el sentido pasivo del Dasein frente al esenciarse del ser a partir del imperar de lo donado.

No obstante, pese a que no podemos negar que hay un cambio en la acentuación del aspecto dinámico al aspecto estático -respecto del lugar en donde se emplaza el sentido originario del esenciarse. Opinamos, tal como indica Thomas Sheehan en su artículo "Dasein", ${ }^{43}$ que ambos aspectos permanecen en

[40] El concepto de cercanía es muy importante para la vertiente de estudio del pensar de Heidegger de carácter topológico. Algunos pensadores como Emil Kettering (1987), Jeff Malpas (2006) y Alfredo Rocha de la Torre (2007), entre otros, le dan una centralidad especial a este concepto porque consideran que a partir de él se configura la experiencia fundamental de la comprensión del ser a partir de temas como: el poetizar, el pensar, el lenguaje, el habitar, la serenidad, el tiempo, el espacio, la cuaternidad, etc.

[41] Heidegger, Martin. Heraklit. Der Anfang des abendländischen Denkens, op. cit., pp. 17-171.

[42] Heidegger, Martin. Zur Sache des Denkens, op. cit., 19.

[43] Publicado en Dreyfus, Hubert, Wrathall, Mark A. (eds.), A Companion to Heidegger, USA

THÉMATA. Revista de Filosofía, Nº49 enero-junio (2014) pp.: 51-74

doi: 10.12795/themata.2014.i49.03 
juego a la hora de definir los factores que determinan la estructura constitutiva de dicho sentido -sea en el primero como en el segundo período de la obra de Heidegger. Pues bien, por medio de la perspectiva de la inter-referencia se plasma en el Ereignis la reciprocidad entre lo activo y lo pasivo a partir de la integración de lo pensado en la Ontología Fundamental y el Seynsdenken. Esto es, lo activo de Sein und Zeit (la proyección del Dasein) y lo pasivo del Seynsdenken (la recepción de la yección del Seyn).

Ahora bien, para que el claro emerja y se mantenga en lo abierto, precisamos comprender cómo se emplaza e instituye en el Da del Dasein este imperar. Dos son los temples que ensamblan de forma apropiada en la estructura del Ereignis el claro: el éxtasis (Entrückung) y el encantamiento (Berückung). Ambos temples se entrelazan para la puesta esclarecedora de la ofrenda y en-caminan un proyecto, a la vez que son encaminados por la temporalización y la espacialización de lo yectado. Por ende, como adelantamos previamente, la aparición de estos temples depende de la Zeit-Raum-Gefüge. Heidegger examina esta cuestión en el apartado (d) del cuarto ensamble de los Beiträge, la fundación -die Gründung. Allí se introduce en las formas originarias del tiempo y el espacio de la estructura del Ereignis. El filósofo presenta al ensamble de tiempo-espacio ${ }^{44}$ como el ámbito originario en el que se concentra la dinámica conflictiva del Ereignis. La estructura éxtasis-encantamiento alude, entonces, al surgir-de y la pertenencia-a en el fenómeno. Así pues, el claro se propicia en el instante (Augenblick) en el que se efectúa la doble Kehre o la Kehre im Ereignis. Éste plasma la singularidad del Ereignis como fenómeno en el que se consuma la verdad como acontecer. A propósito Heidegger nos dice: "El tiempo-espacio es la acaecida abertura de las vías de inversión [Kehrungsbahnen] del Ereignis, de la Kehre entre pertenencia y llamada-a, entre abandono del ser y hacer señas (¡el estremecerse de la oscilación del ser mismo!). Cercanía y lejanía, vacío y donación, impulso y vacilación, todo ello no puede ser concebido tempo-espacialmente desde las representaciones usuales." 45

Por lo tanto, dadas las condiciones particulares del fenómeno y la caracterización del "otro pensar", Heidegger insiste en la destrucción hermenéutica de estos conceptos para una reformulación apropiada en el Ereignis-Denken. Heidegger indica que: "El ocultarse se eleva a través del claro, y sólo cuando esto acaece, cuando lo conflictivo [das Strittige] en su intimidad domina totalmente al ' $D a$ ', puede lograrse salir del ámbito indeterminado y como tal para nada asido del re-presentar y vivenciar e intentar la instancia del Da-sein." ${ }^{4}$

Blackwell Publish, 2005, p. 200.

[44] Traducimos tiempo-espacio y no espacio-tiempo porque Heidegger dice que primero se nombra al tiempo, el componente más importante de esta configuración.

[45] Heidegger, Martin. Beiträge zur Philosophie (Vom Ereignis), op. cit., p. 372.

[46] Ibidem, p. 349.

THÉMATA. Revista de Filosofía, No49 enero-junio (2014) pp.: 51-74

doi: 10.12795/themata.2014.i49.03 
Más adelante dice que: "El claro para el ocultamiento no mienta la sobreasunción de lo oculto y su dispensa y transformación en inoculto, sino justamente la fundación del fundamento abismoso para el ocultamiento (el vacilante rehúso). ${ }^{47}$ Con esto quiere decir, que más allá del proceso del surgimiento de lo desoculto de lo oculto, importa la oscilación entre ambas instancias y el trasfondo indeterminado que las sostiene. Ante todo, el filósofo sostiene que la estabilidad en la instancia oscilante se obtiene con una preparación que se gana con la meditación en el decir pensante del Ereignis.

Finalmente, el filósofo resuelve presentar la dinámica de los temples de la siguiente manera. El tiempo está aquí experimentado como éxtasis e inauguración. En la yección del Seyn ya se desplaza oculto el fundamento (del ente) como posibilidad de una ex-posición fundante, en el sentido de un poner-fuera que reúne lo yectado con el Dasein. Por ende, la ekstatische Zeitlihckeit des Daseins ya estaba contenida en la yección del Seyn. Heidegger explica: "En tanto el arrojador proyecta, inaugura la apertura, descubre a través de la inauguración que él mismo es el arrojado y nada produce sino coger al vuelo [aufzufangen] el contrabalanceo en el ser, es decir, ingresa en éste y con ello en el Ereignis." 48

Por otro lado, el tiempo en tanto extasiante-inaugurante es con ello en sí, a la vez, emplazador. Una vez que la yección se yecta hacia el Dasein, se asienta en el $D a$ en donde el claro se dispone en lo abierto. Este espaciamiento instala la dimensión clareante en la unidad de los tres éxtasis temporales que presta la localidad pre-espacial (die vorräumliche Ortschaft) para el encantamiento del Dasein ante la yección del Seyn; encantamiento que le es concedido por la horizontale Temporalität des Seyns. Con el encantamiento se sostiene en su total estructura el instante en el que se presencia el claro en el ocultarse y, por ende, la temporalización es sostenida como a-bismo originario, es decir, como el entregarse fundante que no es fundamento (Un-Grund). Pues bien, el encantamiento admite la posibilidad de la donación como posibilidad aconteciente de lo que se entrega y sustrae. El encantamiento es el emplazamiento del Ereignis ${ }^{49}$ en "el entre" oscilante.

Todo esto puede resumirse en el críptico pero, ahora, aclarado pasaje del autor de los Beiträge que transcribimos a continuación: "El sitio del instante [die Augenblicksstätte], singularidad y acceso del más claro éxtasis al ámbito del hacer señas desde el suave encantamiento de lo que se rehúsa-va-

[47] Ibidem, p. 352 .

[48] Ibidem, p. 304.

[49] Estamos de acuerdo con la tesis de Jeff Malpas acerca de que la noción de Ereignis es topológica, en el sentido de que intenta “....articular un lugar [Place], no a partir de la derivación de un principio o fundamento previo, sino por el contrario a través de su carácter diferenciante y, a la vez, unitivo. [...] El Ereignis no es algo aparte de la reunión de los elementos que lo componen." (Heidegger's Topology. Being, Place, World, Cambridge, The MIT Press, 2006, p. 222.)

THÉMATA. Revista de Filosofía, Nº49 enero-junio (2014) pp.: 51-74 doi: 10.12795/themata.2014.i49.03 
cila, cercanía y lejanía en la decisión, el dónde y cuándo de la historia del ser aclarándose-ocultándose desde el acaecimiento de la disposición fundamental de la retención. Ésta y la experiencia fundamental del $D a$ y de este modo del tiempo-espacio." ${ }^{50}$ La experiencia que se abre tempo-espacialmente viene dada por la unidad originaria de tiempo-espacio. Para que esencie el fundamento del ente en el Da-sein tiempo y espacio se separan en un transplazamiento o remoción (Verrückung) a partir del cual el éxtasis (Entrückung) y el encantamiento (Berückung) se dan, concretándose la llamada-a y la pertenencia, que hacen acontecer, propiciar y apropiar el claro.

\section{Fundamentación del Ereignis por medio del tiempo}

A partir de la perspectiva de la continuidad de la obra de Heidegger presentamos la clave hermenéutica de la inter-referencia (Wechselbezug) entre la Ontología Fundamental y el Ereignis-Denken. Esta clave nos posibilitó advertir que la relación Seyn-Dasein en la estructura del Ereignis presupone o, mejor dicho, requiere de la analítica existencial para efectuar la, ya varias veces mencionada, kehriger Bezug des Seyns.

En sentido estricto, para que se temporalice de forma originaria la donación del ser se requiere de la proyección del Dasein. Por consiguiente, el tiempo originario que fundamenta el fenómeno entero de la donación como realización de la síntesis que une y separa en la forma contra-tendiente de los opuestos al Seyn y el Dasein, se concreta -como explicaremos a continuación- a través del cruce de die ekstatische Zeitlihckeit des Daseins y die horizontale Temporalität des Seyns. De este modo, la dificultad que se visualiza al final de Sein und Zeit a partir de la idea de una fundamentación de la temporalidad del Dasein en un tiempo originario (que Heidegger resuelve en los Beiträge de esta manera), se plasma gracias a la condición que establece para comprender a la Kehre, a saber, la de relacionar lo pensado en Heidegger I y II.

Ahora bien, para comprender el cruce entre die ekstatische Zeitlihckeit des Daseins y die horizontale Temporalität des Seyns debemos aproximarnos nuevamente al ámbito originario de la Zeit-Raum-Gefüge porque allí se pre-figura la síntesis mencionada. ${ }^{51}$ En los apartados previos analizamos en detalle cómo se traspasan las dimensiones de apropiación y expropiación. Por ende, ya adelantamos la relación que entre éxtasis y encantamiento tempo-espacializa el claro en el Da del Dasein. No obstante, falta explicitar un poco más cómo se co-pertenecen allí Zeitlichkeit y Temporalität.

[50] Heidegger, Martin. Beiträge zur Philosophie (Vom Ereignis), op. cit., p. 375.

[51] En torno a esta cuestión véase el libro de Paola Coriando: Der letzte Gott als Anfang. Zur abgründigen Zeit-Räumlichkeit des Übergangs in Heideggers "Beiträge zur Philosophie", München, Wilhelm Fink Verlag, 1998, pp. 72-76.

THÉMATA. Revista de Filosofía, No 49 enero-junio (2014) pp.: 51-74

doi: 10.12795/themata.2014.i49.03 
Ciertamente, Heidegger no ofrece un análisis preciso y aclaratorio acerca de la forma como el ámbito abismal del Ereignis se temporaliza y espacializa. Su manera de abordar el esenciarse de la verdad en lo que llama el sitio del instante (Augenblicksstätte) no es del todo esclarecedora. Más bien nos lega una serie de notas complicadas de las que podemos rescatar ciertos lineamientos básicos para caracterizar este horizonte previo que posibilita el fundamento del ente en su totalidad. Por este motivo, trataremos de realizar la tarea cuasi imposible de traducir o interpretar la exposición de Heidegger sobre este asunto. En parte este problema aparece porque la tonalidad abismal que adquiere el proceso de esencialización del acontecer impide presentar estas estructuras previas que limitan la experiencia del Dasein en términos de una determinación del sentido. La reformulación de lo trascendental se enmarca aquí en una relación más compleja, el Ereignis. Por lo tanto, la descripción del ámbito originario se realiza a partir del ensamble indeterminado que permite la fundación de la verdad. ${ }^{52}$ Por todo esto, se complica mostrar lo inaparente. No obstante, intentaremos dar con ello, es decir, con lo que Heidegger transmite al respecto en los Beiträge.

Como señalamos anteriormente, al ámbito originario y abismal le conciernen formas de temporalización (Zeitigung) y espacialización (Räumung) distintas a las versiones tradicionales que de él emergen. En el abismo se encuentran aunados espacio y tiempo para, luego, separarse y configurar al mundo a través de la espacialización y la temporalización derivadas. Un rasgo esencial del ámbito abismal es el contra-balanceo (Gegen-Schwung) constante a partir del cual se esencia la verdad como claro para el ocultamiento. Este contra-balanceo se caracteriza, justamente, por la falta de una determinación acabada y la carencia de un fundamento. En efecto, la indeterminación de este movimiento pendular es sumamente importante en el fenómeno del Ereignis porque de ello depende la amplitud de posibilidades que se abren en el juego de contraposición y transplazamiento de las partes.

En el abismo acontece el transplazamiento (Verrückung) que disgrega al espacio y el tiempo. El tiempo se transplaza bajo el desplazamiento del éxtasis (Entrückung) y el espacio se transplaza bajo el emplazamiento del encantamiento (Berrückung). Heidegger identifica al éxtasis con la temporalidad del Dasein y al encantamiento con la temporariedad del Seyn. Pues bien, en Sein und Zeit la temporalidad presenta la constitución exstática del Dasein y la temporariedad re-posiciona al Dasein en la esencialización del Seyn. No obstante, tanto la temporalización como la espacialización originarias se concretan en el cruce Seyn-Dasein. En este sentido, Heidegger sostiene que el tiempo se desplaza o yecta en tres modos que se sintetizan con los tres éxtasis tempo-

[52] Es importante subrayar que para Heidegger el acontecer del ser es fundante pero no fundamentador.

THÉMATA. Revista de Filosofía, Nº49 enero-junio (2014) pp.: 51-74 doi: 10.12795/themata.2014.i49.03 
rales del Dasein y el espacio se emplaza de forma encantadora en un modo que concuerda con la espacialización del Dasein.

Así pues, en el caso de la temporalización del tiempo nos encontramos con el cruce de las tres dimensiones temporales que se desplazan en el ámbito abismal como: la espera del Dasein de un futuro arribo del ser, el recuerdo del Dasein de la pertenencia de un haber-sido en el ser y el olvido del Dasein por el abandono del ser en el presente. En resumen, la unidad de la triple estructura del tiempo que conocemos como la Zeitlichkeit des Daseins se sintetiza con el fenómeno de espacialiazación del espacio que nos brinda la cuarta dimensión del Ereignis, la cercanía (die Nähe). En este caso, la Temporalität des Sey$n s$ emplaza -gracias al sostén abarcador que proporciona el encantamiento- la unidad de la triple estructura dimensional del tiempo en el claro. De esta manera se concreta el fenómeno entero de la temporalización del Ereignis.

No obstante, cuando Heidegger presenta estas formas originarias de temporalización y espacialización no deja de aclarar que el tiempo sigue imponiéndose sobre el espacio porque, a los ojos del filósofo, lo funda. Pareciera que a fin de procurarse una espacialización se requiere de una temporalización emplazadora, pues en el tiempo originario ya está contenida la unidad tiempo-espacio. Por lo tanto, en los Beiträge el filósofo retoma como fundamento primero del acontecer al tiempo. Tiempo y ser siguen en intrínseca comunión. Después de todo, según Heidegger el tiempo implica movilidad; la movilidad eminente de todo fenómeno de esencialización. Este es el tiempo que posibilita el envío y la sustracción, es decir, el fenómeno complejo de donación que por su continua ocultación -surgir de lo oculto- concede ser a los múltiples entes.

En definitiva, la temporalización del tiempo (Zeitigung des Zeit) inherente al fenómeno de donación no hace más que desplegar la diferencia como contraposición de las partes que se co-pertenecen en el camino. Esta comprensión del tiempo como dador del ser, emplazador del sitio del instante ${ }^{53}$ (Augenblicksstätte) en el que se funda la verdad, es la respuesta a la pregunta que formuló Heidegger al final de Sein und Zeit: “¿Hay un camino que conduzca del tiempo original al sentido del ser? ¿El tiempo, se manifiesta como el horizonte del ser?" 54 Si seguimos la descripción del tiempo que ofrecen los Beiträge, nos encontramos con una respuesta afirmativa. Heidegger se esfuerza por describir este horizonte originario en el que se instala y sostiene el fenómeno de la donación, que aquí se estructura, fundamentalmente, a partir del tiempo.

[53] Tal como Mario Gómez destaca en el artículo "La temporariedad originaria del ser (Seyn) en los Beiträge zur Philosophie: Entre el Instante y la Eternidad": "El instante ya no es ahora el momento de temporalización de la propiedad tal como anunciaba Sein und Zeit, sino que excediendo ese modo de ser temporal se revela como el relampaguear de la eternidad, siempre esquiva y sustractiva. Este es el aporte (Beitrag) fundamental de todos los aportes a la filosofía (Beiträge zur Philosophie)..." (Publicado en Catoggio, Leandro y Parente, Diego. (comps.) Decir el abismo. Lecturas de Heidegger y su obra de la década del '30, Mar del Plata, EUDEM, 2010, p. 241)

[54] Heidegger, Martin. Sein und Zeit, Tübingen, Max Niemeyer Verlag, 1960, p. 437.

THÉMATA. Revista de Filosofía, Nº49 enero-junio (2014) pp.: 51-74

doi: 10.12795/themata.2014.i49.03 
Investigaciones acerca de la estructura conflictiva del Ereignis en Beiträge zur philosophie de Martin Heidegger

\section{A modo de conclusión: la diferencia en el Ereignis}

Hemos llegado al último apartado del trabajo. Aquí presentaremos brevemente algunas consideraciones en torno al punto central de la diferencia en el Ereignis. No obstante, no queremos dejar de mencionar que queda mucho por explorar, porque no podemos pretender abordar íntegramente el asunto. A partir de este estudio sólo intentamos sentar las bases de una posible lectura que esperamos continuar.

En la última parte de los Beitrage titulada “das Seyn” Heidegger se detiene en el problema de la diferencia, todavía denominada allí "diferencia ontológica”. El autor advierte la necesidad de pasar por la diferencia para realizar la pregunta fundamental (Grundfrage), ${ }^{55}$ aquella que había sido planteada en Sein und Zeit. De esta forma, vuelve sobre sus pasos para cerrar el libro en conexión con la antigua formulación del problema.

El filósofo tuvo claro, desde un comienzo, que la interrogación por el ser no podía responderse, o siquiera, afrontarse sin antes aclarar el trasfondo fenomenológico desde dónde se hacía la pregunta. El tratamiento que Heidegger emprende, entonces, enfatiza la paradoja inherente a la donación del ser. El esenciarse del ser determina su esencia. Por ende, la pregunta siempre partió del cómo y no del qué. Esto se debe a que la propia esencia del ser es el resultado de su esenciarse; del darse y el sustraerse que resguarda la diferencia.

Bajo esta óptica, insiste nuevamente en que la diferencia ontológica tiene que ser experimentada en la estructura del "Da-sein" a través de su disposicionalidad (Stimmtheit) al Seyn. ${ }^{56}$ Esta vuelta no implica abandonar los Beiträge, sino mantenerlos en diálogo con el trabajo anterior. De esta manera, a partir del concepto auto-interpretativo de la inter-referencia el filósofo aborda su obra por entero y la plasma en el Ereignis. Debido a que con éste expone cómo se produce efectivamente el esenciarse como diferencia. La diferencia tiene su origen en el movimiento de contraposición de las partes que mantienen en armonía las dimensiones de ocultación y desocultación explicitadas en la estructura conflictiva del Ereignis. Esta concepción de la diferencia -que luego presenta el filósofo como conciliación o resolución (Austrag) ${ }^{57}$ termina

[55] Al respecto Heidegger plantea: "La pregunta por el ser como pregunta fundamental no habría concebido nada de lo suyo propio más cuestionable, si no fuera impelida de inmediato a la pregunta por el origen de la 'diferencia ontológica'. La distinción de 'ser' y 'ente', que el ser se destaque del ente, sólo puede tener su origen en el esenciarse del ser.” (Beiträge zur Philosophie (Vom Ereignis), op. cit., p. 465)

[56] Ibidem, p. 469.

[57] En el trabajo de 1957 "Die onto-theo-logische Verfassung der Metaphysik" publicado en Identität und Differenz Heidegger presenta a la diferencia como la resolución [Austrag] desencubridora y encubridora de ser y ente. El filósofo dice que: "En la resolución reina el claro de lo que se cierra velándose y da lugar a la separación y reunión de la sobrevenida y la llegada." (Identidad y Diferencia- Identität und Differenz, op. cit., p. 140)

THÉMATA. Revista de Filosofía, No 49 enero-junio (2014) pp.: 51-74 doi: 10.12795/themata.2014.i49.03 
de mostrar el sentido contradictorio de la donación y la necesidad de captar ambas partes sin reducir el fenómeno a una de ellas. Heidegger piensa a la diferencia y en el proceso descubre que lo mejor es mantener el origen conflictivo de esta cuestión. De esta manera, decide portar (tragen) o gestar (austragen) la diferencia. 


\section{Referencias bibliográficas}

\section{Obras de Martin Heidegger}

Wegmarken, Frankfurt am Main, Vittorio Klostermann, GA 9, 1976.

Unterwegs zur Sprache, Frankfurt am Main, Vittorio Klostermann, GA 12, 1985.

Zur Sache des Denkens, Frankfurt am Main, Vittorio Klostermann, GA 14, 2007. Die Grundprobleme der Phänomenologie, Frankfurt am Main, Vittorio Klostermann, GA 24, 1989.

Hölderlins Hymnen. „Germanien” und der „Rhein”, Frankfurt am Main, Vittorio Klostermann, GA 39, 1999.

Einführung in die Metaphysik, Frankfurt am Main, Vittorio Klostermann, GA 40, 1983.

Heraklit. Der Anfang des abendländischen Denkens, Frankfurt am Main, Vittorio Klostermann, GA 55, 1994.

Beiträge zur Philosophie (Vom Ereignis), Frankfurt am Main, Vittorio Klostermann, GA 65, 1994.

Besinnung, Frankfurt am Main, Vittorio Klostermann, GA 66, 1997.

Die Geschichte des Seyns, Frankfurt am Main, Vittorio Klostermann, GA 69, 1998.

Über den Anfang, Frankfurt am Main, Vittorio Klostermann, GA 70, 2005.

Das Ereignis, Frankfurt am Main, Vittorio Klostermann, GA 71, 2009.

Identidad y Diferencia- Identität und Differenz, edición bilingüe, trad. H. Cortés y A. Leyte, España, Anthropos, 1990. (Sigue la versión alemana de la edición de Verlag Günther Neske, 1957)

Sein und Zeit, Tübingen, Max Niemeyer Verlag, 1960.

\section{Escritos de comentaristas y otros filósofos}

Berciano, Modesto. Ereignis: la clave del pensamiento de Heidegger. En Thémata. Revista de filosofía, $\mathrm{N}^{\circ}$ 28, 2002, pp. 48-69.

Catoggio, Leandro y Parente, Diego. (comps.) Decir el abismo. Lecturas de Heidegger y su obra de la década del '30, Mar del Plata, EUDEM, 2010.

Capobianco, Richard. Engaging Heidegger, Toronto, University of Toronto Press, 2010. Coriando, Paola Ludovica. Der letzte Gott als Anfang. Zur ab-gründigen Zeit-Räumlichkeit des Übergangs in Heideggers "Beiträge zur Philosophie", München, Wilhelm Fink Verlag, 1998.

Crowell, Steven, Malpas, Jeff. (eds.) Transcendental Heidegger, California, Stanford University Press, 2007.

Dreyfus, Hubert, Wrathall, Mark A. (eds.), A Companion to Heidegger, USA Blackwell Publish, 2005. 
Emad, Parvis. On the way to Heidegger's Contributions to Philosophy, Wisconsin, University of Wisconsin Press, 2007.

Guignon, Charles (ed.), The Cambridge Companion to Heidegger, New York, Cambridge University Press, 1993.

Herrmann, Friedrich Wilhelm von. Heideggers "Grundprobleme der Phänomenologie". Zur "Zweiten Hälfte" von "Sein und Zeit", Frankfurt am Main, Vittorio Klostermann, 1991. (trad. La se2gunda mitad de Ser y Tiempo. Sobre los problemas fundamentales de la Fenomenología de Heidegger, Madrid, Trotta, 1997.)

- Wege ins Ereignis. Zu Heideggers "Beiträgen zur Philosophie”, Frankfurt am Main, Vittorio Klostermann, 1994.

Kettering, Emil. Nähe. Das Denken Martin Heidegger, Pfullingen, Verlag Günther Neske, 1987.

Malpas, Jeff. Heidegger's Topology. Being, Place, World, Cambridge, The MIT Press, 2006.

Rocha de la Torre, Alfredo. El concepto de cercanía en Martin Heidegger. En Eidos, $\mathrm{N}^{\circ}$ 7, 2007, pp. 48-86.

Volpi, Franco. Martin Heidegger. Aportes a la filosofía, Madrid, Maia Ediciones, 2010. Walton, Roberto. El camino hacia lo inaparente. En Alfredo Rocha de la Torre (ed.) Heidegger hoy. Estudios y perspectivas, Buenos Aires, Grama, 2011.

- El 'viraje' en los 'Beiträge' de M. Heidegger y en los Manuscritos C de E. Husserl. En Investigaciones Fenomenológicas, № 9, 2012, pp. 89-115

Xolocotzi, Ángel. Fundamento, esencia y Ereignis. En torno a la unidad del camino del pensar de Martin Heidegger. En Éndoxa: Series filosóficas, ํㅜ 20, Madrid, UNED, 2005, pp. 733-744. 